\title{
Mixed-Use Facility Model for the Welfare of the EIderly Based on Lifestyle
}

\author{
Sung Jun Park ${ }^{1}$, Hyunsoo Lee*² and Mi Jeong Kim ${ }^{3}$ \\ ${ }^{1}$ Assistant Professor, Department of Interior and Environmental Design, Keimyung University, Republic of Korea \\ ${ }^{2}$ Professor, Department of Interior Architecture and Built Environment, Yonsei University, Republic of Korea \\ ${ }^{3}$ Assistant Professor, Department of Housing and Interior Design, Kyung Hee University, Republic of Korea
}

\begin{abstract}
This research aims to develop a mixed-use facility model for the wellbeing of the elderly, responding to the changes caused by the recent trends of low birthrate, growth of the aging population, and baby boomers entering their senior years. It is expected that mixed-use facilities for the elderly in the current context should be integrated, including other generations and providing extensive beneficial services to all social classes for universal welfare. Using a customized questionnaire, we examined baby boomers' demands on welfare services associated with spaces, and characterized their lifestyles. Based on their lifestyles, a mixed-use facility model for the welfare of the elderly is proposed, suggesting a spatial configuration framework as an integrated system of various functions, generations and managements. This research can be used as a basis for constructing a customized welfare service environment for the elderly. By applying the proposed method, various spatial configurations can be developed for mixed-use facilities for the welfare of the elderly.
\end{abstract}

Keywords: mixed-use; welfare facility; elderly; lifestyle; planning

\section{Introduction}

Life expectancy is anticipated to increase from the range of 46-89 years to 66-93 years in the 21 st century (UN, 2004). Further, the proportion of the world's population in the over 65 age group (the retirement age in most countries) is estimated to quadruple from $8 \%$ to $32 \%$, and in the 80 or over age group to double from $8.5 \%$ to $17 \%$ within 7 or 8 decades. Concurrently, the birthrate is declining, reducing the proportion of children (Chan et al., 2009). Dishman (Dishman, 2004) proposed four requirements to cope with the current trend of increase in the elderly demographic: promote healthy behaviors, detect diseases at an early stage, improve treatment compliance and provide support for informal care giving. These requirements can be met by achieving the concept of 'aging in place', i.e. assisting elderly people to continue to live in their homes (Harmo et al., 2005). Most older persons defer or avoid institutionalizing as long as possible, and then seek wellness in safety and independence (Chan et al., 2008; Kim \& Kazuoki, 2010). Accordingly, many strategies such as community centers and health

*Contact Author: Hyunsoo Lee, Professor,

Department of Interior Architecture and Built Environment, Yonsei University, 419 Samsung Hall 134 Sinchon-Dong, Seodaemun-Gu, Seoul, 120-479, Republic of Korea

Tel: +82-2-2123-3136 Fax: +82-2-313-3139

E-mail: hyunsl@yonsei.ac.kr

(Received October 10, 2012 ; accepted July 23, 2013) support have been proposed for elderly people's comfort and healthy living in their own home or community.

South Korea has already become an aging society (Kim et al., 2009). In terms of the concept of generation as a demographic cohort, those who make up the aging population were mainly born during the restoration period after the Korean War, from the mid 1950 s to the early 1960 s. The period with the greatest birth rate is denoted the "baby boom period", showing a dramatic acceleration in population growth. When the baby boomers enter their senior years, it is possible that they will have different characteristics and demands from those of the previous generations of the elderly. They have specific social and historical experiences; therefore, new social welfare policies and strategies suitable for them should be explored and addressed during the architectural planning stage, for instance, of the provision of mixed-use facilities for the elderly at a district or community level.

This research aims to develop a mixed-use facility model for the wellbeing of the elderly, responding to the changes caused by the recent trends of low birthrate, growth in the aging population, and baby boomers entering their senior years. There have been various types of social welfare facilities, each targeting a separate group, e.g. the elderly, children, the disabled, etc. The government has generally focused on supporting social welfare for low socioeconomic classes. However, our assumption is that mixed-use 
facilities for the elderly in the current context should be integrated, including other generations and providing extensive beneficial services to all social classes for universal welfare. We expect that, through the integrated facility, synergic interaction could enable the elderly to experience social cohesion with other community members across social classes and generations, leading to a sustainable society in a larger sense.

To suggest a space composition for integrated mixeduse facilities for the elderly, we used a customized questionnaire to examine the demands of the aging baby boomers on welfare services associated with spaces, and characterized their lifestyles. Based on the baby boomers' lifestyles, a mixed-use facility model for the welfare of the elderly is proposed, integrating functions, generations and management within the spaces.

\section{Related Works}

\subsection{Baby Boomers and Lifestyle}

Baby boomers make up about $14.6 \%$ of Korea's population (Statistics, 2010). As senior members of society, they have now started to retire from work, which has increased the proportion of those considered to be elderly in our society. Changes caused by this new, aging generation might affect the economy, housing types, consumption patterns, etc., eventually causing a growing welfare investment or cost in our society (Byeon, 2010, Jeong, 2010, Kim, 2010). Thus, it is necessary to prepare for the aging population of baby boomers and provide planning strategies for welfare of the elderly in the future. To achieve this, the characteristics and lifestyles of the baby boomers must first be characterized, as they might be different from those of current elderly people.

In the field of marketing, an emphasis has been placed on research dealing with lifestyle in order to investigate consumers' consumption behaviors. Lifestyle evaluation tools have been developed, targeting all generations in the areas of hotel and tourism management, architecture and housing planning (Wee-Kean Fong et al., 2007), commercial facilities, leisure activities, etc. These tools focus on the measurement of valued aspects of life, living mode, consumption behavior, attitude, etc. associated with lifestyle. In particular, there have been several studies on specialized space planning, centered on the identification of service needs and the development of new housing models (Chang et al., 1997, Oh, 2006, Young-Sook, 2009, Kim and Kim, 2009, Yoon and Park, 2010). Further, some research has specifically dealt with the lifestyles of the elderly in order to apply it to town planning, welfare services, interface design, etc. for the elderly (Kim and Park, 2004, Ha et al., 2007, Ko and Hwang, 2008, Yoo et al., 2007, Shin and Park, 2010). In general, measured items of lifestyles proposed by the previous research consist of factors associated with family life, health, financial status, social interaction, cultural and leisure activity, etc.

Gerontographics is another approach to characterizing the elderly gerontographics; this focuses on needs, features, lifestyle and behaviors. This approach considers various dimensions associated with aging and external environmental conditions affecting the behavior of the elderly (Moschis, 1993). Compared with lifestyle models based mainly on psychological factors, gerontographics considers factors associated with biological aging in addition to social aging. Based on a survey of people over 55, Moschis (Moschis, 1993 ) proposed four lifestage segments for the silver market: healthy hermits, ailing outgoers, frail recluses and healthy indulgers. The proposed model, consisting of 26 items, effectively reflects biophysical and psycho-social aging factors. Twelve items from the model could be seen to be related to major factors characterizing baby boomers' lifestyles.

\subsection{Welfare Facilities and Complexation}

Welfare facilities are generally defined as social facilities supporting the weak in a society (Lee, 2009) However, this research, which targets all generations and social classes, considers five social services associated with culture and leisure, medical and health treatment, life-long education, protection and living support (Seoul, 2010). Accordingly, various functions for the elderly, children (youth), day-care, singleparent families and social welfare should be integrated in a welfare facility. An integrated facility could provide the elderly with more opportunities to socialize with other generations, to take up new jobs after retirement, to enjoy leisure activities, to participate in community services, etc. By adjusting welfare facilities to accommodate the changes caused by the low birthrate and growth in the aging population, mixed-use facilities for the elderly-combining social welfare, medical and health, and public services-would emerge, specifically targeted at baby boomers. With other welfare services, an integrated facility emphasizing welfare for the elderly could be effectively utilized for baby boomers' social interaction and productivity.

Trials have been conducted integrating various facilities for cultural activities, social services, physical exercise, etc. in a welfare facility (Kim, 1999). He proposed a complexation of facilities for culture and welfare to promote the efficient management of public services, and suggested strategies for this based on a location analysis. In particular, many attempts at complexation have been made in Japan while establishing a service infrastructure for the welfare of the elderly, to cope with the rapidly aging society. Mixed-use facilities for the elderly in Japan could minimize the changes necessary to the residential environment for the elderly, reduce the effects of the elderly's physical and psychological disabilities, secure their psychological stability, and enable a sustainable facility management (Kim, 2009). Park, 
(2009) analyzed case studies of mixed-use facilities for the elderly in Japan, and then proposed strategies for spatial configuration and planning to encourage social interaction among different generations. For instance, social interaction could be encouraged by spatial planning that improves the chances of residents coming across one another in mixed-use buildings (Lee, 2011). The complexation can be effected by integrating various welfare facility functions, such as social welfare, education, medical services, other social facilities, community services, etc.

\section{Research Methodology}

This research conducted a questionnaire survey to investigate baby boomers' lifestyles and needs from welfare services. A customized questionnaire was developed based on the literatures on lifestyle and case studies of mixed-use facilities. To reduce the effect of education and income levels on the result, subjects for the survey were limited to inhabitants in Seoul.

\subsection{Specifying Measure Items}

The questionnaire comprises items in two survey areas: baby boomers' lifestyle evaluation and service needs. Five lifestyle factors were derived from factors proposed by previous studies from 2000 to 2010 , and factors of gerontographics (Moschis, 1993) specializing in silver markets. Further, 25 items for lifestyle evaluation were extracted from previous studies' measure items, as shown in Table 1.

\begin{tabular}{|c|c|c|}
\hline Factors & No & Items \\
\hline $\begin{array}{l}\text { Culture \& } \\
\text { Leisure }\end{array}$ & $\begin{array}{l}\text { Q01 } \\
\text { Q02 } \\
\text { Q03 } \\
\text { Q04 } \\
\text { Q05 }\end{array}$ & $\begin{array}{l}\text { Interested in leisure \& culture activities } \\
\text { Play sports \& take up a hobby for enjoyment } \\
\text { Interested in dynamic leisure activities (exercise, climbing) } \\
\text { Interested in static leisure activities (reading, watching TV) } \\
\text { Interested in sharing leisure activities with the younger } \\
\text { generation }\end{array}$ \\
\hline $\begin{array}{c}\text { Health \& } \\
\text { Aging }\end{array}$ & $\begin{array}{l}\text { Q07 } \\
\text { Q08 } \\
\text { Q09 } \\
\text { Q10 }\end{array}$ & $\begin{array}{l}\text { Afraid of developing an age-related disease, such as } \\
\text { arthritis and cardiac disorder } \\
\text { Afraid of having problems with hearing and sight } \\
\text { Be healthy enough to manage household chores by myself } \\
\text { Try to look younger than one's age } \\
\text { Afraid of being dependent as one grows older }\end{array}$ \\
\hline $\begin{array}{c}\text { Social } \\
\text { Interaction }\end{array}$ & $\begin{array}{l}\text { Q11 } \\
\text { Q12 } \\
\text { Q13 } \\
\text { Q14 } \\
\text { Q15 }\end{array}$ & $\begin{array}{l}\text { Capable of being involved in charities \& making donations } \\
\text { Sociable and able to make new friends } \\
\text { Sensitive to others' evaluation of myself } \\
\text { Interested in participating in voluntary activity } \\
\text { Places a big emphasis on intergenerational communication }\end{array}$ \\
\hline $\begin{array}{l}\text { Education } \\
\text { \& Job }\end{array}$ & $\begin{array}{l}\text { Q16 } \\
\text { Q17 } \\
\text { Q18 } \\
\text { Q19 } \\
\text { Q20 }\end{array}$ & $\begin{array}{l}\text { Need to master using new products } \\
\text { Need to learn about health \& cultures } \\
\text { Interested in learning to become information technology } \\
\text { literate } \\
\text { Interested in joining a job re-entry program after retirement } \\
\text { Enjoy learning new skills }\end{array}$ \\
\hline $\begin{array}{l}\text { F a mily - } \\
\text { oriented } \\
\text { Life }\end{array}$ & $\begin{array}{l}\text { Q21 } \\
\text { Q22 } \\
\text { Q23 } \\
\text { Q24 } \\
\text { Q25 }\end{array}$ & $\begin{array}{l}\text { Interested in overcoming the death of loved ones } \\
\text { Satisfactory life after retirement } \\
\text { Have a person who can advise on preparation for aging } \\
\text { Prefer installment plan when paying with credit cards } \\
\text { Spend plenty of time with spouse and children }\end{array}$ \\
\hline
\end{tabular}

As shown in Table 2,, to investigate the baby boomers' needs for welfare services associated with spaces, five categories, each consisting of 50 items, were developed based on previous research, case studies and related laws on elderly welfare facilities, social welfare facilities, etc.

\subsection{Analyzing Questionnaire Data}

The data analysis procedure is as follows: Firstly, the reliability of the questionnaire was evaluated by Cronbach's alpha. Secondly, general characteristics of respondents were analyzed. Thirdly, the major factors of respondents' lifestyle were deduced by factor analysis.

Table 2. Categories and Items for Service Needs

\begin{tabular}{|c|c|c|}
\hline Category & No & Items \\
\hline \multirow{10}{*}{$\begin{array}{l}\text { Culture \& } \\
\text { Leisure } \\
\text { (A) }\end{array}$} & 01 & Indoor exercise (aerobics, yoga, health, etc.) \\
\hline & 02 & Travel information (climbing, traveling, etc.) \\
\hline & 03 & Swimming \\
\hline & 04 & Billiards, table tennis \\
\hline & 05 & Basketball/badminton \\
\hline & 06 & Sports (soccer, gate ball) \\
\hline & 07 & Community events \\
\hline & 08 & Themed exhibition \\
\hline & 09 & Movie, performance \\
\hline & 10 & Music/video \\
\hline \multirow{10}{*}{$\begin{array}{l}\text { Medical } \\
\text { Treatment } \\
\& \\
\text { Health } \\
\text { (B) }\end{array}$} & 01 & Health improvement \\
\hline & 02 & Health counseling \& examination \\
\hline & 03 & Physical therapy \\
\hline & 04 & Theme treatment (seeing/hearing/teeth, etc.) \\
\hline & 05 & Nursing the elderly \\
\hline & 06 & Public health support (emergency/treatment) \\
\hline & 07 & Geriatrics care \\
\hline & 08 & Child care (emotion \& development care) \\
\hline & 09 & Drug abuse prevention \& cure (youth, the elderly) \\
\hline & 10 & Seminars on health, nutrition education \\
\hline \multirow{10}{*}{$\begin{array}{l}\text { Life-long } \\
\text { Education } \\
\text { (C) }\end{array}$} & & Hobby/culture class (singing, dance, calligraphy) \\
\hline & 01 & Social community (the elderly/youth/children/women) \\
\hline & $\begin{array}{l}02 \\
03\end{array}$ & Book and information resources \\
\hline & 03 & Education for youth \& children (reading, computer, study) \\
\hline & 04 & Lecture \& information exchange on babies \\
\hline & 05 & Education preventing child/elderly abuse \\
\hline & $\begin{array}{l}06 \\
07\end{array}$ & $\begin{array}{l}\text { Information service for the elderly (new job after } \\
\text { retirement) }\end{array}$ \\
\hline & 08 & Information service for children/youth/single mothers \\
\hline & 09 & Regional society contribution \\
\hline & 10 & Technology education (single mothers/youth) \\
\hline \multirow{10}{*}{$\begin{array}{l}\text { Protection } \\
\& \text { Care } \\
\text { (D) }\end{array}$} & 01 & Elderly day-care \\
\hline & 02 & Short-term baby/infant care \\
\hline & 03 & Elderly cohabitation support \\
\hline & 04 & Abused children protection \\
\hline & 05 & Child-care support \\
\hline & 06 & Elderly nursing support \\
\hline & 07 & Single mother protection \\
\hline & 08 & Mother (father)-son protection \\
\hline & 09 & Housing support for the elderly living alone \\
\hline & 10 & Children independent living support \\
\hline \multirow{10}{*}{$\begin{array}{l}\text { Living } \\
\text { Support } \\
\text { (E) }\end{array}$} & 01 & Post office, bank, drug store \\
\hline & 02 & Bath, restaurant, beauty parlor \\
\hline & 03 & Café, internet \\
\hline & 04 & Mart, convenience store, department store \\
\hline & 05 & Family relationship improvement (counseling, education) \\
\hline & 06 & Multi-cultural family support \\
\hline & 07 & Intergenerational interaction \\
\hline & 08 & Daily life guidance (the elderly/children/youth) \\
\hline & 09 & Public administrative facility \\
\hline & 10 & Public open space \\
\hline
\end{tabular}

Fourthly, cluster analysis was conducted using the major lifestyle factors. Fifthly, through factor analysis of service items, the type of the mixed-use facilities was classified for each lifestyle group. Finally, the diagram of the spatial composition of the mixeduse facility was derived for each lifestyle, based on the correlation among mixed-use classifications, and the characteristics of welfare services. As shown in 
Table 3., the Cronbach's alpha for variables' internal consistency is more than 0.8 , thus the reliability of the questionnaire was validated.

Respondents' general characteristics, such as gender, age, income, housing type, occupation and education level were investigated. Of 224 respondents, 109 (48.7\%) were men and 115 (51.3\%) were women. The age range was between 47 and 56 years of age with overall distribution. Respondents' income level was comparatively high, where 121 people $(54 \%)$ earned more than 4 million won monthly and 182 (81.3\%) owned their houses. The occupations were varied: 92 people $(41.1 \%)$ were general employees, including bank clerks, nurses, teachers, managers, etc. and 43 people (19.2\%) were self-employed, for instance, as drivers and shop owners. Twenty-five people (11.2\%) were professionals such as doctors, professors, judges and accountants, and 19 people $(8.5 \%)$ worked in the service sector, including stores, restaurants, etc. Fifteen people $(6.7 \%)$ were high-ranking officials, CEOs and executives in organizations and companies. Only 6 people $(2.7 \%)$ worked as cleaners, housekeepers and laborers. Regarding the level of education, 158 participants $(70.5 \%)$ graduated from universities or higher institutions.

\begin{tabular}{cccc}
\multicolumn{2}{c}{ Table 3. Reliability of the Questionnaire } & \multicolumn{2}{c}{$\mathrm{n}=224$} \\
\hline $\begin{array}{c}\text { Classification } \\
\text { Items for } \\
\text { Lifestyle }\end{array}$ & $\begin{array}{c}\text { Cronbach's } \\
\text { Alpha }\end{array}$ & $\begin{array}{c}\text { Cronbach's Alpha Based on } \\
\text { Standardized Items }\end{array}$ & $\begin{array}{c}\text { Items } \\
\text { (Variables) }\end{array}$ \\
$\begin{array}{c}\text { Items for } \\
\text { Service Needs }\end{array}$ & 0.836 & 0.841 & 24 \\
\hline
\end{tabular}

\section{Lifestyle Categorization and Elderly Classification}

Factor analysis, using principal component analysis by varimax rotation, was conducted to characterize respondents' lifestyles. The result of factor analysis was significant since the Kaiser-Meyer-Olkin value for sampling adequacy was 0.797 and the value of the Barlett test was 0.00. Factor loading was more than 0.4 , and eigenvalue was more than 1.0. Initially, 24 variables were selected, but 4 variables were dropped due to poor reliability and validity, thus 20 variables were used finally. Table 4. shows 5. major factors related to lifestyles revealed by the factor analysis. Five factors associated with lifestyle explained $57 \%$ of the variance. Even though the explanation percentage was slightly low, all variables, excluding one, showed high file loadings with values greater than 0.5 . Accordingly, the suitability of the categorization of variables was verified.

To classify the respondents centered on the lifestyle factors, cluster analysis was conducted. This analysis categorizes cases as clusters that are relatively homogeneous within themselves, on the basis of a defined set of variables. In this research, 4 groups were determined as clusters using K-means clustering, one of the non-hierarchical procedures. All clusters were statistically significant. The validity of clusters was
Table 4. Lifestyle Categorization $\mathrm{n}=224$

\begin{tabular}{|c|c|c|c|c|}
\hline Factors & Items & Factor Loading & $\begin{array}{c}\text { Eigenvalues } \\
\text { (Variance Rates) }\end{array}$ & Reliability \\
\hline \multirow{6}{*}{$\begin{array}{l}\text { Future Self- } \\
\text { development }\end{array}$} & Q16 & 0.777 & \multirow{6}{*}{$\begin{array}{c}3.009 \\
(15.046)\end{array}$} & \multirow{6}{*}{0.801} \\
\hline & Q17 & 0.765 & & \\
\hline & Q18 & 0.738 & & \\
\hline & Q20 & 0.587 & & \\
\hline & Q19 & 0.541 & & \\
\hline & Q21 & 0.527 & & \\
\hline \multirow{4}{*}{$\begin{array}{c}\text { Outgoing } \\
\text { Culture \& } \\
\text { Leisure }\end{array}$} & Q2 & 0.858 & \multirow{4}{*}{$\begin{array}{c}2.494 \\
(12.471)\end{array}$} & \multirow{4}{*}{0.765} \\
\hline & Q3 & 0.808 & & \\
\hline & Q1 & 0.708 & & \\
\hline & Q12 & 0.402 & & \\
\hline \multirow{4}{*}{$\begin{array}{c}\text { Social } \\
\text { Interaction }\end{array}$} & Q14 & 0.664 & \multirow{4}{*}{$\begin{array}{c}2.072 \\
(10.36)\end{array}$} & \multirow{4}{*}{0.644} \\
\hline & Q15 & 0.659 & & \\
\hline & Q8 & 0.629 & & \\
\hline & Q5 & 0.526 & & \\
\hline \multirow{3}{*}{$\begin{array}{c}\text { Health } \\
\text { Concerns }\end{array}$} & Q7 & 0.821 & \multirow{3}{*}{$\begin{array}{l}1.928 \\
(9.64)\end{array}$} & \multirow{3}{*}{0.635} \\
\hline & Q6 & 0.767 & & \\
\hline & Q10 & 0.586 & & \\
\hline \multirow{3}{*}{$\begin{array}{l}\text { Family- } \\
\text { oriented Life }\end{array}$} & Q11 & 0.717 & \multirow{3}{*}{$\begin{array}{l}1.898 \\
(9.492)\end{array}$} & \multirow{3}{*}{0.545} \\
\hline & Q23 & 0.674 & & \\
\hline & Q25 & 0.548 & & \\
\hline
\end{tabular}

Table 5. Classification of the Elderly, Centered on Lifestyle Factors $\mathrm{n}=224$

\begin{tabular}{|c|c|c|c|c|c|}
\hline Classification & $\begin{array}{c}\text { Passive } \\
\text { Social-oriented }\end{array}$ & $\begin{array}{c}\text { Active } \\
\text { Stable-oriented }\end{array}$ & Active Ego & Passive Ego & $F$ \\
\hline No & $\begin{array}{c}39 \\
(17.4 \%)\end{array}$ & $\begin{array}{c}73 \\
(32.6 \%)\end{array}$ & $\begin{array}{c}60 \\
(26.8 \%)\end{array}$ & $\begin{array}{c}52 \\
(23.2 \%)\end{array}$ & (Sig) \\
\hline $\begin{array}{l}\text { Future Self- } \\
\text { development }\end{array}$ & -1.177 & .038 & .440 & .322 & $\begin{array}{c}34.39 \\
(0.000)\end{array}$ \\
\hline $\begin{array}{c}\text { Outgoing } \\
\text { Culture \& Leisure }\end{array}$ & -.857 & .125 & .486 & -.093 & $\begin{array}{c}18.24 \\
(0.000)\end{array}$ \\
\hline $\begin{array}{c}\text { Social } \\
\text { Interaction }\end{array}$ & .387 & .087 & .063 & -.484 & $\begin{array}{c}6.763 \\
(0.000)\end{array}$ \\
\hline $\begin{array}{l}\text { Health } \\
\text { Concerns }\end{array}$ & -.132 & .549 & .424 & -1.160 & $\begin{array}{r}63.36 \\
(0.000)\end{array}$ \\
\hline $\begin{array}{c}\text { Family- } \\
\text { oriented Life }\end{array}$ & -.379 & .878 & -.911 & .102 & $\begin{array}{l}74.396 \\
(0.000) \\
\end{array}$ \\
\hline
\end{tabular}

verified through discriminant analysis with a $95.1 \%$ accuracy rate of discrimination. Table 5. shows the results of cluster analysis.

The lifestyle groups can be characterized as follows: Group 1, 'Passive social-oriented', is mainly interested in one lifestyle factor, seeking 'social interaction', not 'future self-development', 'outgoing culture \& leisure', 'family-oriented life' or 'health concerns'. Compared to other groups, group 1 shows more negative and passive attitudes to lifestyle factors. By referring to the results of the cluster analysis, it became clear that respondents from low income and education levels belonged to this group. Group 2, 'Active stableoriented', is mainly interested in two factors, 'health concerns' and 'family-oriented life'. In addition, they have a positive response to 'outgoing culture \& leisure' activities compared to other groups. However, they are less conscious of activities related to 'future selfdevelopment' and 'social interaction'. Group 3, 'Active ego', is intensely interested in the activities related to 'future self-development' and 'outgoing culture \& leisure' compared to other groups. In addition, they are very concerned with health problems. However, they show less interest in activities for social interaction and family life. The cluster analysis found that there were a comparatively higher proportion of professionals in respondents belonging to this group. It appears that 
they may be keen to develop themselves and to enjoy culture and leisure activities in their lives. Group 4, 'Passive ego', is much less interested in activities related to 'health concerns' compared to other groups. Similar to group 1 ('Passive social-oriented'), group 4 also shows a passive attention to lifestyle factors. However, there is a difference in that group 4 is somewhat concerned with activities related to 'future self-development' and 'family-oriented life' rather than 'social interaction'.

\section{A Proposed Mixed-Use Facility Model for the Welfare of the Elderly Based on Lifestyle}

We developed a mixed-use facility model for the welfare of the elderly, suggesting a framework of spatial configuration, based on baby boomers' lifestyles and service needs associated with spaces. The facility model adopted the concept of complexation, and thus proposed mixed types of spaces supporting various functions, generations and management systems. The framework of spatial configuration was constructed based on the mixed types of spaces and the proposed welfare services extracted from the questionnaire survey. The proposed mixed-use facility could play an important role for the elderly by offering more opportunities for new jobs, and by integrating various functions of welfare facilities, such as health-care, education and culture, and leisure. Further, the model aims to activate social integration by promoting generational interactions among the elderly, the youth, and children, thereby enriching life experience for all ages. To demonstrate the proposed model, one type of mixed-use facility model for the welfare of the elderly, specifically for group 3, 'Active ego', is described in the following sections. With the same approach, the other three types of mixed-use facility models could be developed, each applied to every lifestyle group.

\subsection{The Mixed-Use Facility Model Process}

The process of developing the mixed-use facility model, consisting of four steps, is described in Fig.1. Firstly, a questionnaire survey needs to be conducted to investigate the elderly's lifestyle and welfare service needs. Secondly, items for lifestyle evaluation and service needs in spaces must be specified. Through factor and cluster analyses, the items for lifestyle evaluation need to be categorized, forming several clusters. Then, required spaces for each lifestyle group need to be deduced from service needs with values greater than 3.93. Therefore, the proposed model in this research contains the elderly's preferred spaces for needs. Thirdly, to propose the framework of spatial configuration for each lifestyle group, the mixed-use types of spaces need to be classified by factor analysis. Fourthly, a mixed-use facility model for the welfare of the elderly, suggesting a spatial configuration as a combination of high-correlated welfare services, can be proposed.

\subsection{A Mixed-Use Facility Model for 'Active Ego'}

For the 'Active Ego' group, 34 of their service needs items, extracted from the items showing greater than 3.93 mean values, were analyzed by factor analysis. As shown in Table 6., for the 'Active Ego' group, eight factors emerged for the mixed type of spaces related to medical treatment and health, protection

\begin{tabular}{|c|c|c|c|c|c|c|}
\hline No & Factors & Services & Spaces & Needs & $\begin{array}{r}\text { Factor } \\
\text { Loading }\end{array}$ & Reliability \\
\hline \multirow{10}{*}{01} & \multirow{10}{*}{$\begin{array}{c}\text { D 7ea+ } \\
\text { B 2ea+ } \\
\text { E 1ea }\end{array}$} & $\mathrm{D}$ & 08 & 3.93 & 0.907 & \multirow{10}{*}{0.925} \\
\hline & & D & 05 & 3.95 & 0.902 & \\
\hline & & $\mathrm{D}$ & 04 & 4.20 & 0.803 & \\
\hline & & $\mathrm{D}$ & 10 & 3.93 & 0.695 & \\
\hline & & $\mathrm{D}$ & 03 & 4.08 & 0.652 & \\
\hline & & $\mathrm{D}$ & 09 & 4.22 & 0.633 & \\
\hline & & B & 08 & 3.93 & 0.606 & \\
\hline & & B & 06 & 4.08 & 0.529 & \\
\hline & & $\mathrm{D}$ & 06 & 4.33 & 0.502 & \\
\hline & & $\mathrm{E}$ & 05 & 4.00 & 0.477 & \\
\hline \multirow{6}{*}{02} & \multirow{6}{*}{$\begin{array}{c}\text { B 5ea+ } \\
\text { C 1ea }\end{array}$} & $\mathrm{B}$ & 03 & 4.37 & 0.828 & \multirow{6}{*}{0.877} \\
\hline & & B & 02 & 4.45 & 0.727 & \\
\hline & & B & 01 & 4.33 & 0.681 & \\
\hline & & B & 05 & 4.45 & 0.59 & \\
\hline & & B & 07 & 4.43 & 0.569 & \\
\hline & & $\mathrm{C}$ & 07 & 4.28 & 0.563 & \\
\hline \multirow{5}{*}{03} & \multirow{5}{*}{$\begin{array}{c}\text { E 4ea }+ \\
\text { B 1ea }\end{array}$} & B & 09 & 4.02 & 0.689 & \multirow{5}{*}{0.82} \\
\hline & & E & 09 & 4.10 & 0.65 & \\
\hline & & $\mathrm{E}$ & 10 & 4.03 & 0.621 & \\
\hline & & E & 07 & 3.98 & 0.581 & \\
\hline & & E & 08 & 4.00 & 0.571 & \\
\hline \multirow{3}{*}{04} & \multirow{3}{*}{ E 3ea } & $\mathrm{E}$ & 04 & 4.00 & 0.839 & \multirow{3}{*}{0.852} \\
\hline & & $\mathrm{E}$ & 01 & 4.23 & 0.78 & \\
\hline & & $\mathrm{E}$ & 02 & 4.07 & 0.727 & \\
\hline \multirow{3}{*}{05} & $\mathrm{C} 1 \mathrm{ea}+$ & $\mathrm{C}$ & 01 & 4.23 & 0.741 & \multirow{3}{*}{0.821} \\
\hline & $\mathrm{D}_{1 \mathrm{ea}}+$ & $\mathrm{D}$ & 01 & 4.08 & 0.682 & \\
\hline & B lea & B & 04 & 4.25 & 0.608 & \\
\hline \multirow[b]{2}{*}{06} & \multirow{2}{*}{ A 2ea } & $\mathrm{A}$ & 03 & 3.95 & 0.743 & \multirow{2}{*}{0.686} \\
\hline & & A & 01 & 4.25 & 0.664 & \\
\hline \multirow{3}{*}{07} & Aleat & $\mathrm{A}$ & 04 & 3.95 & 0.598 & \multirow{3}{*}{0.627} \\
\hline & B leat & B & 10 & 3.98 & 0.523 & \\
\hline & C 1ea & $\mathrm{C}$ & 03 & 4.02 & 0.427 & \\
\hline \multirow{2}{*}{08} & \multirow{2}{*}{ A $2 \mathrm{ea}$} & $\mathrm{A}$ & 02 & 4.07 & 0.795 & \multirow{2}{*}{0.537} \\
\hline & & A & 09 & 4.02 & 0.556 & \\
\hline
\end{tabular}

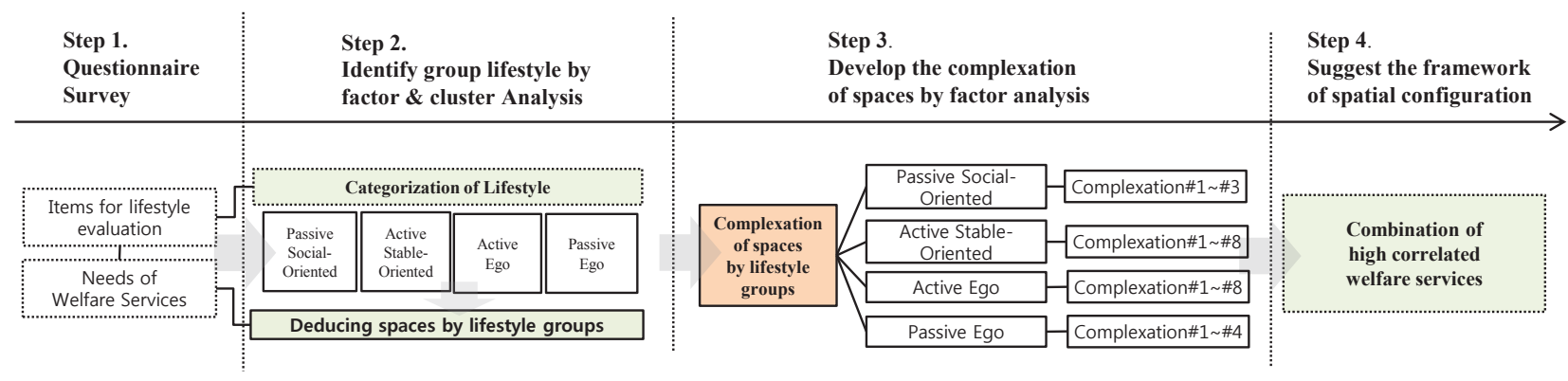

Fig.1. Development Process of the Mixed-Use Facility Model Process 


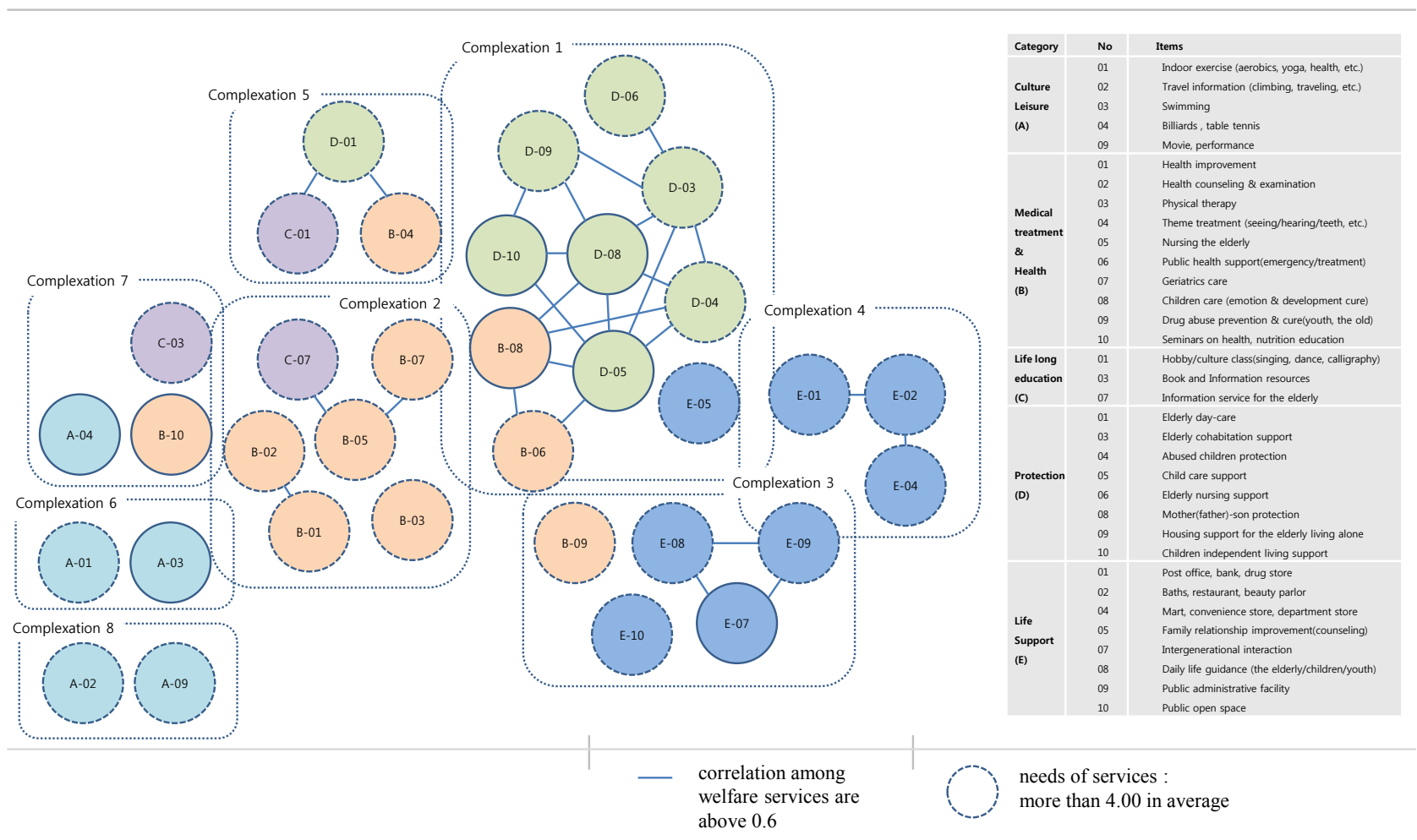

Fig.2. The Framework of Spatial Configuration of the Mixed-Use Facility Model for 'Active Ego' Lifestyle

and care, culture and leisure, and living support. They show a marked tendency to include services related to medical treatment and health and life-long education in the mixed types of spaces, reflecting a strong will to develop themselves in the future.

The first type integrates spaces related to medical treatment and life-long education centered around spaces for general protection and care services. The majority of the spaces support people in general including adults, babies and children rather than the elderly exclusively. Spaces for medical treatment and health involve children's hospitals and public health support. One example of spaces for life-long education is social communities to enhance relationships among members. Spaces affording protection and care services provide not only housing support for elderly cohabitation and the elderly who live alone, but also other social welfare spaces for child-care, abused children protection, and mother (father) and children support.

The second type mixes spaces related to lifelong education centered around spaces for medical treatment and health. This type consists of general spaces affording health counseling and examination, physical therapy, and health improvement for the public, and specialized spaces supporting the elderly such as nursing facilities and geriatrics hospitals. As spaces for life-long education, information centers for the elderly can be included, offering opportunities for new jobs after retirement and organizing activities that exercise both their brains and bodies.

The third type is the complexation of spaces for medical treatment and health services centered around spaces for life-support services. One example of these spaces is associated with the prevention and treatment of drug abuse as a preclusive approach reducing social problems caused by diseases. Spaces associated with life-support services include civic facilities, public open spaces for rest, etc. Recently, remodeling of local government facilities has been considered to promote social interaction among generations, provide counseling on daily life problems, offer services for culture, leisure and education, and not be limited solely to administrative support.

This third type of complexation can be applied to unused spaces in existing public facilities by integrating living support services with medical and health services to promote generation interactions and prevent social problems. Most public facilities are easily accessible for local residents, thus the complexation offers more convenience to local residents.

The fourth type is primarily the complexation of spaces' living support services such as supermarkets, convenience stores, restaurants, etc. The fifth type is the complexation of spaces associated with services for life-long education, protection, and medical treatment and health. This type of complexation is very similar to current facilities for the elderly, but supplements with various therapies for medical and health services. Thus, by intensifying welfare services associated with health, the current facilities for the elderly can be extended. Spaces for hobby/culture classes, elderly day-care, and theme treatment (of seeing, hearing, teeth problems, 
etc.) are included. The sixth type is the complexation of spaces for culture and leisure services. Spaces supporting dynamic activities such as swimming, indoor exercises, yoga, etc. are included.

The seventh type is the complexation of spaces associated with services for medical treatment and health, culture and leisure, and life-long education. Spaces support billiards and table tennis, seminars on health and nutrition, and provision of books and information. The eighth type is the complexation of spaces for culture and leisure services. Spaces are associated with static culture leisure activities such as performance, exhibition and travel information.

Fig.2. illustrates the framework of spatial configuration of the mixed-use facility model for the elderly in the 'active ego' lifestyle group. The eight types of complexations of spaces are combined, based on correlations and classification of welfare services. The correlations range from 0.352 to 0.880 . When the correlations among welfare services are above 0.6 , the spaces associated with the services are connected as shown in Fig.2. It is assumed that when spaces having high correlations are located closely in a facility, the utilization of the facility by users could be enhanced significantly. To sum up, this model for the 'active ego' group highlights the spatial configuration combining spaces related to living support, culture and leisure centered around services associated with life-long education, medical treatment and health, and protection and care.

\section{Discussion and Conclusion}

Based on baby boomers' lifestyles, this research proposed a mixed-use facility model for the welfare of the elderly as an integrated system centered on facility services for the elderly, combined with welfare services for other generations. As current trends reflect an aging population and low birthrate, the pre-elderlyspecifically baby boomers entering their senior yearswere selected as subjects for the questionnaire survey on lifestyle and service needs. The results follow.

The baby boomers' lifestyles were classified into four groups: Passive social-oriented, Active stableoriented, Active ego, and Passive ego. By developing space composition systems based on the baby boomers' welfare service needs, it was identified that the two active baby boomers groups have positive attitudes to the complexation of functions and services for social interaction among various generations. On the other hand, the two passive baby boomers groups seem to have no need for new types of welfare services. That is, the spatial configuration developed based on their service needs closely resembles existing welfare facilities for the elderly. Accordingly, it can be argued that, at town level, the complexation would be initiated best by combining basic services that the passive baby boomers need for their welfare. In a district or wider area, services demanded by the active baby boomers need to be integrated for a mixed-use facility to satisfy their on-going enthusiasm for an active and interesting life. The reason is that welfare spaces derived from the passive baby boomers' service needs include only basic needs, lacking the welfare services demanded by the active baby boomers.

We expect that the classification of baby boomers' lifestyles could be utilized to construct customized welfare environments for the elderly, specializing in or customizing silver markets. There has been little research dealing with the correlations between lifestyles and spaces affording welfare services. For a welfare paradigm shift, the lifestyles of the pre-elderly need to be classified based on their welfare service needs, which would contribute to the development of active and customized service environments for the welfare of the elderly. Further, the proposed mixed-use facility model could provide a specific type of mixeduse services, and then produce a desirable spatial composition for each group of lifestyles. Therefore, integrated facilities for the welfare of the elderly could maximize the efficiency and effectiveness of management and utilization of the spaces by combining existing facilities with other welfare services. Accordingly, this research could be a basis for space composition and planning direction for mixeduse facilities for the welfare of the elderly.

The space configuration in this research is proposed for a horizontal level; thus, the vertical level of space composition needs to be addressed in the mixed-use facility model in the future. Further, more detailed planning factors that can be applied to the development of welfare facilities for the elderly should be explored and discussed for verification in future studies. The methodology adopted for the proposed model could be applied to develop a mixed-use facility model for the elderly in other countries. However, our proposed model can be best adapted for the elderly in Korean society because it was constructed based on the demands of the aging baby boomers on welfare services in Korea. Thus, there would be a limitation in that the model cannot be directly applied for the elderly in other countries.

\section{References}

1) Byeon, M. R. (2010). Baby Boom Generation in Seoul, Change the Future of City. Seoul Development Institute (SDI).

2) Chan, M. et al. (2009). Smart Homes - Current Features and Future Perspectives. Maturitas, 64, pp.90-97.

3) Chan, M. et al. (2008). A Review of Smart Homes - Present State and Future Challenges. Computer methods and programs in biomedicine, 91, pp.55-81.

4) Chang, J.-h. et al. (1997). A Classfication of Residents' Life-Style in Apartment Housing. Journal of Architectural Institute of Korea, 13, pp.13-20.

5) Dishman, E. (2004). Inventing Wellness Systems for Aging in Place. Computer Journal, 17, pp.34-41.

6) Ha, J.-S. et al. (2007). An Influence Analysis of Life Style to Preference Attributes and Selection Intention for Silver Town. Korea Planners, 42, pp.161-177. 
7) Harmo, P. et al. Needs and Solutions-Home Automation and Service Robots for the Elderly and Disabled. The IEEE/RSJ International Conference on Intelligent Robots and Systems (IROS 2005), August, Edmonton Canada.

8) Jeong, K.-H. A Study on Policy Issues for Aging of the Baby Boomers. The Korean Social Security Association, 2010. pp.1-22.

9) Kim, D.-S. \& Kazuoki Ohara. (2010). A Study on the Role of Gardening and Planning of Green Environments for Daily Use by Residents in Senior Housing, Journal of Asian Architecture and Building Engineering, 9, pp.55-61.

10) Kim, I.-H. et al. (2009). An Analysis of Residential Satisfaction for Low-income Senior Citizens. Journal of Asian Architecture and Building Engineering, 8, pp.393-399.

11) Kim, J.-H. \& Park, R.-G. (2004). The Influence of Elder Consumers' Value and Lifestyle on the Intention to Enter the Silver Town. The institute of Knowledge Management, 9, pp.101-125.

12) Kim, J.-K. (2010). A Study on Financial Burdens of Supporting of Baby Boomer. Korea Labor Institute (KLI).

13) Kim, M.-S. \& Kim, M.-H. (2009). University Students's Life Styles and Preferences for Ubiquitous Residential Functions. Journal of the Korean Housing Association, 20.

14) Kim, S.-J. (2009). The Complex of Welfare Facilities for the Elderly in Japan. Journal of Korea Institute of Healthcare Architecture 15, pp.51-55.

15) Kim, S.-W. (1999). A Study on the Complexation of Public Culture \& Welfare Facilities. Seoul Development Institute.

16) Ko, H.-J. \& Hwang, H.-Y. (2008). A Study of Preference Factors for Silvertown Services Based on the Life Style. Journal of the Korean Housing Association 19.

17) Lee, C.-H. (2009). Foundation and Management in Social Welfare Facilities. Changjisa.

18) Lee, J.-H. (2011). Quality of Life and Semipublic Spaces in HighRise Mixed-Use Housing Complexes in South Korea. Journal of Asian Architecture and Building Engineering, 10, pp.149-156.

19) Moschis, G. P. (1993). Gerontographics: A Scientific Approach to Analyzing and Targeting the Mature Market. Journal of Consumer Marketing, 10.

20) Oh, C.-O. (2006). A Study on the Digital Life Style for the Design of Digital Home - Focused on the Residents Who Lived in Busan. Journal of Architectural Institute of Korea, 22, pp.67-75.

21) Park, H.-S. (2009). A Study on the Intergenerational Interaction Space Planning of Age-Integrated Facilities in Japan. Journal of Korea Institute of Healthcare Architecture 15, pp.51-59.

22) Seoul (2010). A Feasibility Study on Building 9988 Welfare Center and Design Study.

23) Shin, W.-K. \& Park, M.-Y. (2010). Priority Analysis of User Interface Evaluation Criteria for the Elderly Based on User's Lifestyle. Journal of Ergonomics Society of Korea, 29, pp.287296.

24) Statistics (2010). The Statistical Study of Yesterday, Today and Tomorrow of Baby Boomer.

25) UN (2004). Un Department of Economic and Social Affairs, Population Division. World Population in 2300. New York.

26) Yoo, C.-K. et al. (2007). Leisure Activities for Aging Population by Their Lifestyles. International journal of tourism sciences:an interdisciplinary social sciences journal, 1, pp.345-363.

27) Yoon, C.-S. \& Park, J.-M. (2010). A Study on the Dwelling Style by Lifestyle of Middle-Aged Married Women. Journal of the Korean Housing Association 21, pp.81-88.

28) Shin, Y.-S. (2009). A Study on Apartment Design Preferences by Resident's Lifestyle. Journal of Architectural Institute of Korea, 25, pp.141-150.

29) Wee-Kean Fong. et al. (2007). Influence of Indirect Lifestyle Aspects and Climate on Household Energy Consumption. Journal of Asian Architecture and Building Engineering, 6, pp.395-402. 